\title{
Linkage and mutational analysis of familial thyroid dysgenesis demonstrate genetic heterogeneity implicating novel genes
}

\author{
Mireille Castanet ${ }^{1,2}$, Sylvia Sura-Trueba ${ }^{1,2}$, Anne Chauty ${ }^{1,2}$, Aurore Carré ${ }^{1,2}$, Nicolas de \\ Roux $^{3,4}$, Simon Heath ${ }^{5}$, Juliane Léger ${ }^{1,6}$, Stanislas Lyonnet ${ }^{7}$, Paul Czernichow ${ }^{1,6}$ \\ and Michel Polak*,1,2,8
}

\begin{abstract}
${ }^{1}$ INSERM U457, Hôpital Robert Debré, Paris, France; ${ }^{2}$ INSERM EMI 0363, Hôpital Necker-Enfants Malades, Paris, France; ${ }^{3}$ INSERM U584, Hôpital Necker-Enfants Malades, Paris, France; ${ }^{4}$ Department of Hormonology and Molecular Biology, Hôpital de Bicêtre, Le Kremlin-Bicêtre, France; ${ }^{5}$ National Center of Genotyping (CNG), Evry, France; ${ }^{6}$ Pediatric Endocrine Unit, Hôpital Robert Debré, Paris, France; ${ }^{7}$ INSERM U393, Hôpital Necker-Enfants Malades, Paris, France; ${ }^{8}$ Pediatric Endocrine Unit, Hôpital Necker-Enfants Malades, Paris, France
\end{abstract}

The pathophysiology of thyroid dysgenesis (TD) is not elucidated yet in the majority of cases. The unexpected familial clustering of congenital hypothyroidism due to TD suggests a genetically determined disorder. Four genes have been hitherto involved in thyroid development, including migration and growth. Three of these encode transcription factors (the thyroid transcription factors 1 and 2 (TTF1 or NKX2.1 and TTF2 or FOXE1) and PAX8) while the other encodes the thyrotropin hormone receptor (TSHR). Some mutations have been reported in patients affected by thyroid defects, which supports the relevance of these four genes in TD. However, their involvement in the general TD population remains questionable. Therefore, to document their involvement, we performed a linkage analysis followed by mutational analysis in 19 multiplex TD families. The LOD score results failed to prove linkage between any of the four genes and the TD phenotype, whatever the postulated mode of inheritance. Manual extended haplotypes showed allele sharing among affected individuals of at least one of these four genes in the majority of families. Nevertheless, mutational analysis did not identify mutations in these cases, arguing in favor of identity by descent and not identity by state. Furthermore, as a main result of the present study, extended haplotypes confirmed by mutational analysis showed that the four genes were excluded in five out of the 19 investigated families, demonstrating the relevance of other genes. In conclusion, the present study demonstrates genetic heterogeneity in the TD disorder and suggests the involvement of novel genes. European Journal of Human Genetics (2005) 13, 232-239. doi:10.1038/sj.ejhg.5201321

Published online 17 November 2004

Keywords: thyroid dysgenesis; familial disorder; TTF1; TTF2; Pax8; TSHR

*Correspondence: Professor M Polak, Paediatric Endocrinology Unit and EMI 0363, Hospital Necker-Enfants Malades, 149 rue de Sèvres, Paris 75015, France. Tel: + 331444948 03; Fax: + 331443816 48; E-mail: michel.polak@nck.ap-hop-paris.fr Received 2 March 2004; revised 9 September 2004; accepted 10 September 2004
Introduction

Thyroid dysgenesis (TD) is the most frequent cause of congenital hypothyroidism $(\mathrm{CH})(85 \% \text { of cases })^{1}$ and results from abnormalities of thyroid gland development including a spectrum of embryogenetic defects such as ectopic thyroid gland, athyreosis and more seldom, thyroid hypoplasia and hemiagenesis. 
The pathogenesis of TD has been as yet elucidated in only a minute fraction of patients and the disorder is usually regarded as sporadic. ${ }^{1}$ Possible roles of autoimmune $^{2}$ (see suppl web) or unidentified environmental factors $^{3,4}$ has been suggested but not confirmed. ${ }^{5,6} \mathrm{~A}$ genetic origin has been suggested since some familial aggregation of $\mathrm{CH}$ due to $\mathrm{TD}$ have been previously occasionally reported $^{7-12}$ (see suppl web), which was confirmed by us in a recent national survey that showed a relatively high proportion of familial cases at $2 \%{ }^{13,14}$

Molecular studies have identified three genes encoding transcription factors expressed in the precursors of the thyroid follicular cells (thyroid-specific transcription factors (TTF1 or TITF1 and TTF2) and Pax 8) that are involved in thyroid gland development. Knockout mouse models confirmed the role of these genes in $\mathrm{TD}$, since mice homozygous for a targeted disruption of Titf1 showed the absence of thyroid tissue, even though the thyroid rudiment is initially formed. ${ }^{15,16}$ Titf2 (-/-) mice displayed either agenesis or ectopy of the thyroid gland. ${ }^{17} \mathrm{Pax} 8(-/-)$ mice showed severe thyroid hypoplasia with the absence of thyroid follicular cells. ${ }^{18}$ In addition to transcription factors, the thyrotropin hormone receptor (TSHR) has been shown to play a role in the growth and differentiation of thyrocytes, as shown by spontaneously occurring mutation in mice that led to severe thyroid hypoplasia. ${ }^{19}$

In humans, impairments of the genes homologous to those described above have been occasionally reported in patients affected by TD. Inactivating mutations of the TSHR gene have been observed in a few cases of thyroid hypoplasia. ${ }^{10,11,20-22}$ Heterozygous mutations in PAX8 have been identified in six families with hypoplasia and/ or ectopy. ${ }^{12,23-25}$ Two homozygous mutations in the TTF2 (or FKHL15 or FOXE1) gene have so far been described in siblings affected by thyroid agenesis associated with cleft palate. ${ }^{26,27}$ Furthermore, recently, heterozygous mutations of TTF1 (or NKX2.1) have been identified in patients with a normal or hypoplastic thyroid gland. ${ }^{28,29}$

Taken together, these data support the involvement of these four genes in thyroid development in mice and humans. However, despite extensive searches for mutation in these candidate genes, only a handful of TD cases have been satisfactorily explained on their basis, and their involvement in the general TD population remains questionable. In addition, a recent study showed discordance in monozygotic twins, which could point to other pathogenetic factors. ${ }^{30}$

Therefore, based on our previous report of familial occurrence of TD, we aimed in this study to ascertain the contribution of TTF1, TTF2, PAX8 and the gene encoding the TSHR in multiplex TD families, using linkage analysis to test whether this familial disorder maps to one or several of these specific candidate gene loci. In addition, mutational analysis was performed to confirm the data of the linkage analysis.

\section{Subjects and methods Patients (Figure 1)}

In all, 19 multiplex TD families including at least two members affected by TD were analyzed. They included a total of 41 affected patients and 98 unaffected relatives. Patients were affected by athyreosis $(n=17)$, ectopy $(n=19)$ or hemiagenesis $(n=5)$, with $(n=37)$ or without $\mathrm{CH}(n=4)$. Families were identified with either only cases of ectopic gland $(n=5)$, athyreosis $(n=5)$ or hemiagenesis $(n=1)$, or a combination of them $(n=8)$. Clinical data on most of the affected patients have been described previously, since 14 out of the 19 families were identified in our previous French national survey. ${ }^{13,14}$ Furthermore, blood samples were collected from members of five other families that were referred to us either after our first familial study or in the following prospective study of Leger et al. ${ }^{31}$

The study was approved by the Faculty Ethics Committee and participants (or their parents in the case of children) provided informed consent.

\section{Methods}

Genomic DNA was prepared from whole blood mononuclear leukocytes.

Linkage analysis (Figures 2 and 3) For genotyping, we used the polymerase chain reaction (PCR)-based hypervariable microsatellite method developed by Weissenbach et $a l .^{32}$ The PCR products were separated in a denaturing $6 \%$ polyacrylamide gel and the dried gel was exposed to an $\mathrm{X}$-ray film for $24-48 \mathrm{~h}$ (PCR conditions will be supplied upon request).

Microsatellite markers, chosen on the basis of their informativity, were selected in the surroundings of the putative region of each candidate locus, obtained from public databases from Genethon (Nature 96), Genmap' 98 (http://www.ncbi.nlm.nih.gov/gnemap99/) and cedar genetic soton (ftp://cedar.genetics.soton.ac.uk/). Of note, subsequent genetic studies have mapped more precisely the TTF2 gene (ch9q22) in the vicinity of the D9S180, Pax8 (ch2q12-14) close to the D2S1985 and TTF1 (ch14q31) between the D9S70 and the D14S75 markers (http:// www.ensembl.org). Only linkage analysis of the TSHR gene (ch14q13) was performed using one intragenic marker TSHR(at). ${ }^{32}$

Extended haplotypes were initially established manually to determine whether the transmission of TD disease could be ascribed (one or two common parental haplotypes shared by the affected members) or rejected (no common haplotypes shared by the affected members) to each of the candidate regions. Linkage study was performed by recombinant mapping analysis. Two-point linkage analyses were performed using the LOD score program from the LINKAGE package. ${ }^{33}$ According to our previous studies ${ }^{13,31}$ and under the hypothesis of genetic homogeneity, analyses 


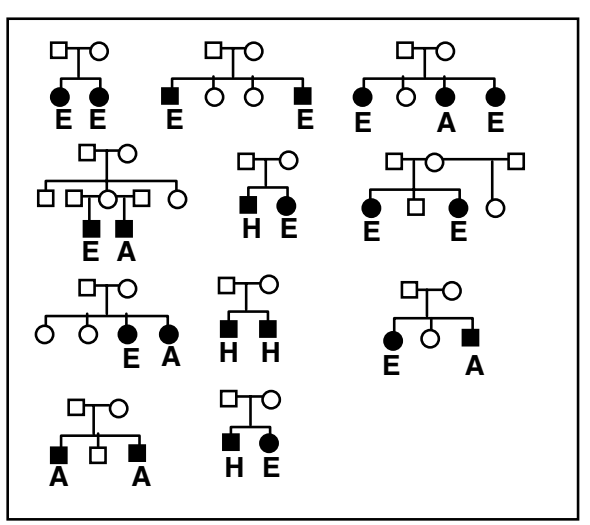

affected sibs $(\mathrm{n}=11)$

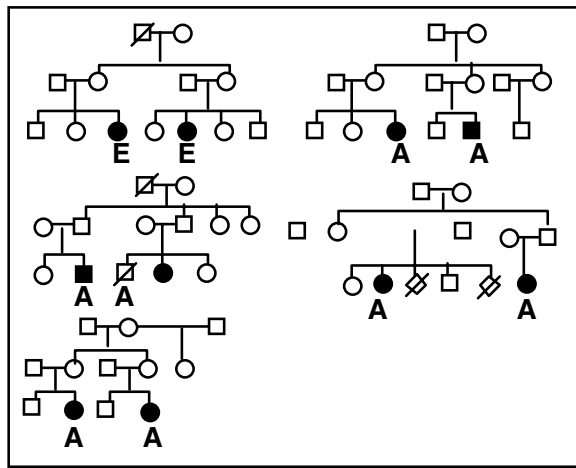

first and second cousins affected $(\mathrm{n}=5)$

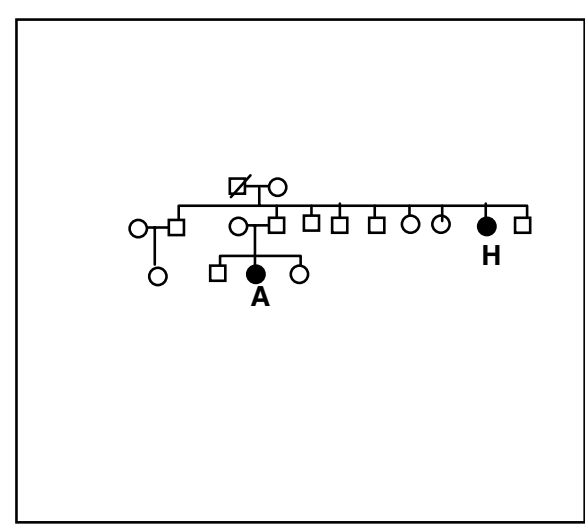

affected aunt and niece $(\mathrm{n}=1)$

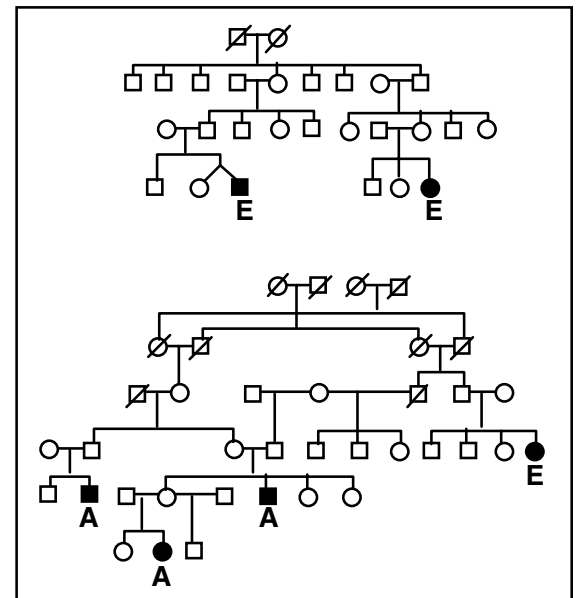

more distant relatives affected $(\mathrm{n}=2)$

Figure 1 Pedigrees and phenotypes in the 19 families with TD $(\mathbf{\square}) \mathrm{CH}$ individuals affected by TD due to either ectopic thyroid gland $(E)$, athyreosis $(A)$ or hemiagenesis $(H)$. Hatched square and circles represent members affected by TD without $\mathrm{CH}$.

were performed assuming either an autosomal dominant mode of inheritance with $20 \%$ of penetrance and a 0.001 frequency of the disease allele or an autosomal recessive mode of inheritance with either 20 or $100 \%$ of penetrance and a 0.01 frequency of the disease.

Mutational analysis To support the results of the linkage analysis, mutational analysis in each of the four studied genes was thereafter performed in one indexaffected subject of the families in which at least one haplotype were shared by the affected members and in all the affected cases of the families in which no haplotypes was shared (Figures 2 and 3). Mutations of PAX8, NKX2.1 and FOXE1 were searched by the SSCP (single-stranded conformational polymorphism) method followed by direct sequencing in cases of anomalous SSCP migration patterns, as described previously. ${ }^{27}$ For the PAX8 and FOXE1, mutational analysis was restricted to the regions encoding the DNA-binding domain of these transcriptions factors, given that all the previously reported mutations were found only in these regions. ${ }^{12,23-29}$ These coding regions were amplified with primers reported previously. ${ }^{12,27}$ For the NKX2.1 analysis, the entire coding region was amplified with primers flanking the three exons of the gene (PCR conditions and sequences of the primers will be supplied upon request). For the TSHR gene, the 10 exons were amplified and directly sequenced as described previously. ${ }^{32}$

\section{Results}

Manual extended haplotype analyses

The combined analysis of genotyping results is summarized in Figure 2. Manual extended haplotypes of the TTF2 region showed that in 10 of the 19 families $(53 \%)$, the affected members shared one $(n=7)$ or two $(n=3)$ haplotypes, suggesting possible involvement of TTF2 in the TD phenotype. In contrast, in nine families, the affected members have inherited different parental 


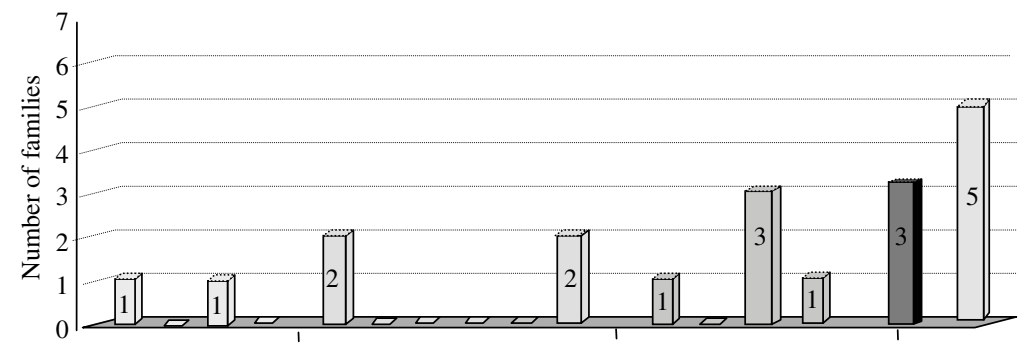

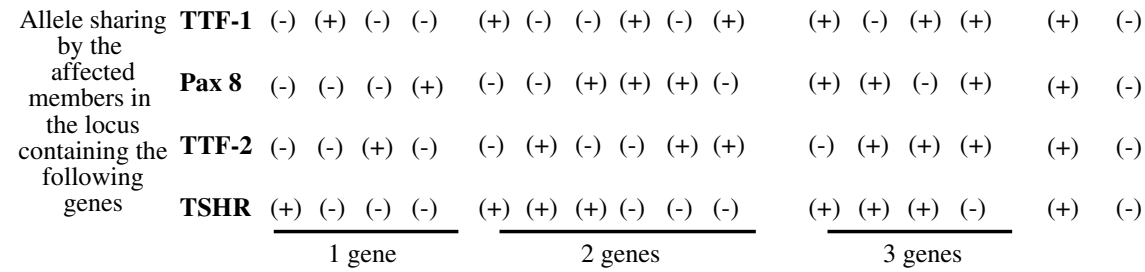

Figure 2 Combined analysis of allele sharing among affected members of the 19 multiplex families with the four candidate gene loci: the number of families is reported according to the allele sharing with each of the studied genes. $(+)$ indicates that at least one haplotype was shared by the affected members and (-) indicates that no haplotype was shared.

haplotypes, which excluded a role of the TTF2 gene in these families (Figures 2 and 3). Similar results were obtained for the TSHR and the TTF1 linkage analyses, with a majority of families showing affected members who shared haplotypes (10 and 12 of the 19 families investigated, respectively) (Figure 2). One common parental haplotype was shared by the affected members in eight of the 10 families in the TSHR region and in nine of the 12 families in the TTF1 region, whereas the same genotype was observed in only two families in the TSHR locus and in three families in the TTF1 locus (data not shown).

In contrast, visual inspection of the genotyping of the PAX8 locus showed the absence of allele sharing among affected members in the majority of the investigated families (74\%). The affected members had at least one common parental haplotype in only five families (26\%). In the 14 other families, the affected members did not have any common haplotype, allowing exclusion of the role of $P A X 8$ in these families (Figure 2).

Taken together, one $(n=2)$ or several loci could be involved in the TD phenotype in 14 out of the 19 investigated families (73\%). Interestingly, in contrast, haplotype analysis did not support linkage to any of the four studied genes in five families (Figures 2 and 3).

Mutational analysis by SSCP, followed by direct sequencing, performed in cases of abnormal migrating bands revealed no mutation in the studied regions of the three candidate gene encoding transcription factors (PAX8, NKX2.1 and FOXE1). In the TSHR gene, one heterozygous mutation in exon $10(\mathrm{R} 310 \mathrm{H})$ was found in one family in which the two affected members shared haplotypes. However, the mutation was identified in the member affected by hemiagenesis, but not in her niece affected by ectopic thyroid gland. This mutation was not found in a population of 450 controls (data not shown).

\section{Statistical analysis}

Maximum two-point LOD scores for the closely spaced markers on each candidate region are shown in Table 1 in the supplementary web information. Whatever the mode of inheritance hypothesized, combining all TD families gave nonsignificant LOD score values for all loci studied.

\section{Genotype-phenotype correlations in TD families}

To test whether the genetic influence was different according to the etiological type of TD, we analyzed the families with ectopy $(n=5)$, athyreosis $(n=5)$, hemiagenesis $(n=1)$ or two different types of TD (mixed families; $n=8$ ) separately. However, subgrouping of families did not change the linkage results. Similarly, the degree of family relationship of the affected relatives did not change the proportion of families with positive or negative linkage (data not shown).

\section{Discussion}

Recent previous investigations in humans have identified genetic alterations in TTF1 or NKX2.1, TTF2 or FOXE1 and $P A X 8$ and in the gene encoding the TSH receptor in some patients affected by TD. ${ }^{10-12,23,25,26,28,29}$ Nevertheless, the pathogenesis of TD remains to be elucidated in the majority of cases. Linkage analyses offer a rapid way to test whether these four previously identified candidate genes are major contributors to TD. So far, only one such linkage analysis has been performed in familial $\mathrm{CH}$, testing 

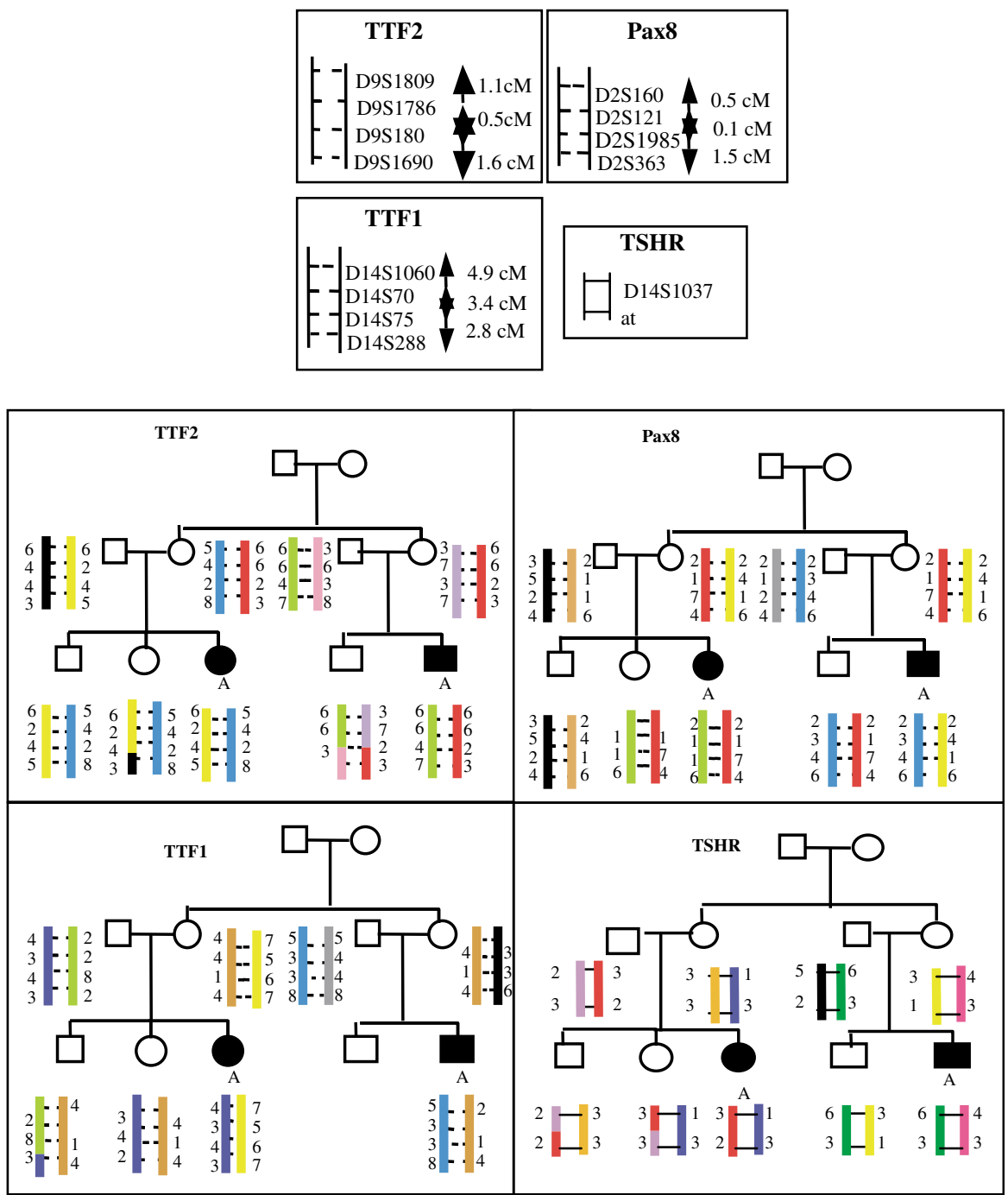

Figure 3 Negative results of linkage analysis for the four candidate loci in one exemplar family. Pedigree structure with extended haplotypes for each of the studied loci are reported in one family in which no haplotypes were shared by the affected members. The genetic mapping of the used markers is indicated for each studied chromosomal region in the inset at the upper corner, with the most centromeric marker at the top and the most telomeric marker at the bottom. Solid symbols indicate subjects affected by athyreosis. Open symbols indicate no thyroid disease.

the association between the TSHR locus and the $\mathrm{CH}$ disorder. ${ }^{10}$

In the present study, the LOD score results did not yield any evidence of linkage between the TD phenotype and either the TSHR locus or TTF1, TTF2 and PAX8. These nonsignificant LOD score values were observed even after subgrouping of families according to the type of TD. Nevertheless, the nonsignificant result of LOD score analysis must be cautiously interpreted since such analysis involves proposing a monogenic model of inheritance pattern of phenotypes and genotypes. The marked clinical variability both within and between the TD families is suggestive of a complex transmission pattern and the model of genetic homogeneity used in this study remains controversial. However, the number of families studied did not allow us to perform LOD score analysis assuming genetic heterogeneity. Furthermore, environmental factors or/and implication of noninheritable postzygotic event cannot currently be excluded as illustrated by discordance for $\mathrm{CH}$ in monozygotic twins. ${ }^{30}$ Thus, genetic susceptibility to TD could lack the simple Mendelian pattern of inheritance and linkage analysis may be insufficient to yield positive results. Therefore, extended manual haplotype analysis could provide additional results.

In the present study, extended haplotypes showed that members with TD phenotype shared alleles of polymorphic 
DNA markers of one or several candidate loci in the majority of family investigated (74\%). This can be due either to identity by state (IBS) or identity by descent (IBD). However, as shown in Figure 3, affected and nonaffected siblings could share the same alleles, which argue in favor of IBD and not IBS. Additionally, such figures were found in other families studies (data not shown). However, IBS cannot be totally excluded as a majority of families with affected siblings shared alleles (10 out of 11 families studied) and as the absence of relevant mutations in the four candidate genes found in affected subjects that shared haplotypes could be in accordance with the low frequency of mutations in these genes, which were to date reported in TD. ${ }^{17-19,30,31,33-40}$ Therefore, the present data do not exclude the role of these genes in the TD disorder. Combined analysis of the linkage study shows, in most cases, families in whom affected members share haplotypes including two or more candidate genes together, which could suggest a polygenic disorder. In favor of this concept, it is worth noting that the combination of the four factors studied is unique in thyroid cells and that they have different actions during thyroid gland development, ${ }^{15-19,35-39}$ (see suppl web). Moreover, some studies show interactions between these candidate genes. For example, TTF2 could be a promoter-specific transcriptional repressor of the TTF1 and PAX8 genes. ${ }^{40}$ In addition, the double Titf1 and Pax 8 heterozygous knockout mice showed abnormalities of thyroid development. ${ }^{41}$ However, no mutation that could be linked to TD was found in any of the four candidate genes. Indeed, the only one identified mutation in the TSHR gene was found in one affected subject but not in the related affected member of the same family, which argues against the responsibility of this mutation in the TD phenotype.

Based on the hypothesis of a purely genetic mechanism of TD, the novel important data of the present study are that we demonstrate the necessary implication of other genes. Indeed, the manual extended haplotypes, confirmed by mutational analysis, allow us to exclude definitely the four up to now identified candidate genes to date in five out of the 19 families investigated. Of note, mutational analysis was restricted for PAX8 and FOXE1 to the regions encoding the DNA-binding domain of these transcription factors, given that all the previously reported mutations were found only in these regions. ${ }^{12,23-29}$ This important finding could suggest that the NKX2.1 (or TTF1), FOXE1 (or TTF2), PAX8 and the TSHR genes might play a simple role of modulating factors in the overall genetic susceptibility to TD. Several other genes may be involved on the basis of their function and their spatiotemporal expression. The NKX2.5 gene (or CSX gene in humans), the HOXB3 or HOXA3 genes, the divergent homeobox gene $H E X$, the hepatocyte nuclear factor $H N F 3$ gene, the GATA6 gene or the eyes absent gene (EYA1) could be relevant candidate genes since they are expressed early during embryogenesis of the thyroid gland and since the impairment of their function may be responsible for TD. ${ }^{42-48}$ In addition, some of these genes may interact with the previously described candidate genes. Indeed, HNF $3 \beta$ could compete with TTF2 for the thyroid-specific genes and activate TTF1, Hoxb3 initiates TTF1 expression. ${ }^{49,50}$ GATA6 has a transcriptional role and activates the TTF1 promoter. ${ }^{51}$ HEX is able to abolish the activating effects of both TTF1 and Pax8. ${ }^{52}$ However, none of these genes is entirely thyroid specific and their impairments in mice usually lead to extra thyroid malformations, ${ }^{45,48,52}$ which have not been frequently found in the TD population. ${ }^{14,53,54}$ Nevertheless, careful studies of the thyroid and extrathyroid phenotype in humans and in mice must be performed to identify further relevant candidate genes. Moreover, performing the cloning of tissue-specific genes ${ }^{55}$ and/or a genome screen in a significant number of familial cases of TD could be interesting additional strategies.

In conclusion, this study supports the view that the genetic determinants of familial TD are heterogeneous. All the known relevant genes TTF1 (or NKX2.1), TTF2 (or FOXE1), Pax 8 and the gene encoding for the TSHR could be involved in some of the studied families, but the present study allows us to exclude their role in some families. Further careful analyses of the phenotype and genotype of the affected patients and of the apparently unaffected relatives in additional studies must be performed in order to elucidate the molecular mechanisms of TD.

\section{Acknowledgements}

We thank T Sanchis (Hôpital Robert Debré, Paris) for maintenance of the DNA bank, M Lathrop (Genethon, Evry) for statistical analyses and $\operatorname{Pr} G$ Van Vliet (Sainte Justine Hospital, Montreal) for careful reading of the manuscript. We also thank the AFDPHE (association pour le dépistage et la prévention des handicaps de l'enfant) and all pediatricians taking part in this study with special contributions from $P$ Barat (Bordeaux), J Berthelot and JM Limal (Angers), M Bost (Grenoble), O Constans (Tours), $R$ Coutant (Angers), S Davidson (Villeneuve St Georges), B Esteva and MC Raux-Demay (Paris), S Fekit (Strasbourg), O Joanny-Flinois and J Peytel (Montbelliard), M de Kerdanet and JP Brizard (Rennes), C Lecointre (Rouen), A Léger (Paris), N Maurin (Marseille), JL Nivelon (Dijon), F Pennaforte and PF Souchon (Reims), C Raynaud-Ravni (St Etienne), M Sautarel (Libourne), C Thalassinos (Paris). This work was supported by a grant from the Evian corporation and an educational grant from the 'Chancellerie des Universités de Paris' to MC and by a CIFRE grant with the help of HRA Pharma to SS-T.

\section{References}

1 Fisher DA: Second International Conference on Neonatal Thyroid Screening: progress report. J Pediatr 1983; 102: 653-654.

2 Van der Gaag RD, Drexhage HA, Dussault JH: Role of maternal immunoglobulins blocking TSH-induced thyroid growth in sporadic forms of congenital hypothyroidism. Lancet 1985; 1: 246-250. 
3 Miyai K, Connely JF, Foley TP et al: An analysis of the variation of incidence of congenital dysgenetic hypothyroidism in various countries. Endocrinol Japon 1984; 31: 77-81.

4 Hall SK, Hutchesson ACJ, Kirk JM: Congenital hypothyroidism, seasonality and consanguinity in the West Midlands, England. Acta Pediatr 1999; 88: 212-215.

5 Working Group on Congenital Hypothyroidism of European Society for Paediatric Endocrinology: Epidemiological Inquiry on Congenital Hypothyroidism in Europe. Horm Res 1990; 34: 1-3.

6 Reijneveld SA, Verkerk PH: No evidence of seasonality of congenital hypothyroidism in the Netherlands. Acta Pediatr 1993; 82: 212-213.

7 Ainger LE, Kelley VC: Familial athyreotic cretinism: report of 3 cases. J Clin Endocrinol Metab 1955; 15: 469-475.

8 Greig WR, Henderson AS, Boyle JA, McGirr EM, Hutchison JH: Thyroid dysgenesis in two pairs of monozygotic twins and in a mother and child. J Clin Endocrinol Metab 1966; 26: 1309-1316.

9 Bamforth JS, Hugues IA, Lazarus JH, Weaver CM, Harper PS: Congenital hypothyroidism, spiky hair, and cleft palate. I Med Genet 1989; 26: 49-51.

10 Abramowicz MJ, Duprez L, Parma J, Vassart G, Heinrichs C: Familial congenital hypothyroidism due to inactivating mutation of the thyrotropin receptor causing profound hypoplasia of the thyroid gland. J Clin Invest 1997; 99: 3018-3024.

11 Biebermann H, Schöneberg T, Krude H, Schultz G, Gudermann T, Grüters A: Mutations of the human thyrotropin receptor gene causing thyroid hypoplasia and persistent congenital hypothyroidism. J Clin Endocrinol Metab 1997; 82: 3471-3480.

12 Macchia PE, Lapi P, Krude $\mathrm{H}$ et al: Pax8 mutations associated with congenital hypothyroidism caused by thyroid dysgenesis. Nat Genet 1998; 19: 83-86.

13 Castanet M, Lyonnet S, Bonaïti-Pellié C, Polak M, Czernichow P, Léger J: Familial forms of thyroid dysgenesis among infants with congenital hypothyroidism. N Engl J Med 2000; 343: 441-442.

14 Castanet M, Polak M, Bonaïti-Pellié C, Lyonnet S, Czernichow P, Léger J: Nineteen years of national screening for congenital hypothyroidism: familial cases with thyroid dysgenesis suggest the involvement of genetic factors. J Clin Endocrinol Metab 2001; 86: 2009-2014.

15 Kimura S, Hara Y, Pineau T et al: The T/ebp null mouse: thyroidspecific enhancer-binding protein is essential for the organogenesis of the thyroid, lung, and ventral forebrain. Genes Dev 1996; 10: $60-69$.

16 Kimura S, Ward JM, Minoo P: Thyroid-specific enhancer-binding protein/thyroid transcription factor 1 is not required for the initial specification of the thyroid and lung primordia. Biochimie 1999; 81: 321-327.

17 De Felice M, Ovitt C, Biffali E et al: A mouse model for hereditary thyroid dysgenesis and cleft palate. Nat Genet 1998; 19: 399-401.

18 Mansouri A, Chowdhury K, Gruss P: Follicular cells of the thyroid gland require Pax8 gene function. Nat Genet 1998; 19: 87-90.

19 Beamer WJ, Eicher EM, Maltais LJ, Southard JL: Inherited primary hypothyroidism in mice. Science $1981 ; 212$ : 61-63.

20 Gagne N, Parma J, Deal C, Vassart G, Van Vliet G: Apparent congenital athyreosis contrasting with normal plasma thyroglobulin levels and associated with inactivating mutations in the thyrotropin receptor gene: Are athyreosis and ectopic thyroid distinct entities ? J Clin Endocrinol Metab 1998; 83: 1771-1775.

21 Tonacchera M, Agretti P, Pinchera A et al: Congenital hypothyroidism with impaired thyroid response to thyrotropin (TSH) and absent circulating thyroglobulin: evidence for a new inactivating mutation of the TSH receptor gene. J Clin Endocrinol Metab 2000; 85: $1001-1008$

22 Bretones P, Duprez L, Parma J, David M, Vassart G, Rodien P: A familial case of congenital hypothyroidism caused by a homozygous mutation of the thyrotropin receptor gene. Thyroid 2002; 11: $977-980$.

23 Congdon T, Nguyen LQ, Nogueira CR, Habiby RL, Medeiros-Neto G, Kopp P: A novel mutation (Q40P) in Pax8 associated with congenital hypothyroidism and thyroid hypoplasia: evidence for phenotypic variability in mother and child. I Clin Endocrinol Metab 2001; 86: 3962-3967.

24 Komatsu M, Takahashi T, Takahashi I, Nakamura M, Takahashi I, Takada G: Thyroid dysgenesis caused by PAX8 mutation: The hypermutability with $\mathrm{CpG}$ dinucleotides at codon 31. J Pediatr 2001; 139: 597-599.

25 Vilain C, Rydlewski C, Duprez L et al: Autosomal dominant transmission of congenital thyroid hypoplasia due to loss-offunction mutation of Pax8. J Clin Endocrinol Metab 2001; 86: 234-238.

26 Clifton-Bligh RJ, Wentworth JM, Heinz P et al: Mutation of the gene encoding human TTF-2 associated with thyroid agenesis, cleft palate and choanal atresia. Nat Genet 1998; 19: 399-401.

27 Castanet M, Park SM, Smith A et al: A novel loss-of-function mutation in TTF-2 is associated with congenital hypothyroidism, thyroid agenesis, and cleft palate. Hum Mol Genet 2002; 11: 2051-2059.

28 Krude H, Schuetz B, Biebermann $\mathrm{H}$ et al: Choreoathetosis, hypothyroidism, and pulmonary alterations due to human NKX2.1 haploinsufficiency. J Clin Invest 2002; 109: 475-480.

29 Pohlenz J, Dumitrescu A, Zundel D et al: Partial deficiency of thyroid transcription factor 1 produces predominantly neurological defects in humans and mice. J Clin Invest 2002; 109: 469-473.

30 Perry R, Heinrichs C, Bourdoux P et al: Discordance of monozygotic twins for thyroid dysgenesis: implications for screening and for molecular pathophysiology. J Clin Endocrinol Metab 2002; 87: 4072-4077.

31 Léger J, Marinovic D, Garel C, Bonaïti-Pellié C, Polak M, Czernichow P: Thyroid developmental anomalies in first degree relatives of children with congenital hypothyroidism. J Clin Endocrinol Metab 2002; 87: 575-580.

32 Weissenbach J, Gyapay G, Dib C, Vignal A et al: A secondgeneration linkage map of the human genome. Nature 1992; 359: 794-801.

33 De Roux N, Misrahi M, Chatelain N, Gross B, Milgrom E: Microsatellites and PCR primers for genetic studies and genomic sequencing of the human TSH receptor gene. Mol Cell Endocrinol 1996; 117: 253-256.

34 Lathrop GM, Lalouel JM, Ott J: Strategies for multilocus linkage analysis in humans. Proc Natl Acad Sci USA 1984; 81: $3443-3446$.

35 Damante G, Tell G, Di Lauro R: A unique combination of transcription factors controls differentiation of thyroid cells. Prog Nucleic Acid Res 2000; 66: 307-356.

36 Kimura S: Role of the thyroid-specific enhancer-binding protein in transcription, development and differentiation. Eur J Endocrinol 1997; 136: 128-136.

37 Van der Kallen CJH, Spierings DCJ, Thijssen JHH, Blankenstein MA, de Bruin TWA: Disrupted co-ordination of Pax8 and thyroid transcription factor-1gene expression in a dedifferentiated rat thyroid tumour cell line derived from FRTL-5. J Endocrinol 1996; 150: $377-382$.

38 Pasca Di Magliano M, Di Lauro R, Zannini M: Pax8 has a key in thyroid cell differentiation. Proc Natl Acad Sci USA 2000; 97: $13144-13149$.

39 Vassart G, Dumont JE: The thyrotropin receptor and the regulation of thyrocyte function and growth. Endocr Rev 1992; 13: $596-611$.

40 Perrone L, Di Magliano MP, Zannini M, Di Lauro R: The thyroid transcription factor 2 (TTF-2) is a promoter-specific DNA-binding independent transcriptional repressor. Biochem Biophys Res Commun 2000; 275: 203-208.

41 Macchia PE, de Felice M, Rosica AM et al: Thyroid dysgenesis is a multigenic disease. The Endocrine Society 2002, [P1-604].

42 Lints TJ, Parsons LM, Hartley L, Lyons I, Harvey RP: Nkx2.5: a novel murine homeobox gene expressed in early heart progenitor cells and their myogenic descendants. Development 1993; 119: 419-431. 
43 Manley N, Capecchi M: Hox group 3 paralogs regulate the development and migration of the thymus, thyroid, and parathyroid glands. Dev Biol 1998; 195: 1-15.

44 Manley N, Capecchi M: The role of Hoxa-3 in mouse thymus and thyroid development. Dev 1995; 121: 1989-2003.

45 Martinez Barbera JP, Clements M, Thomas P et al: The homeobox gene Hex is required in definitive endodermal tissues for normal forebrain, liver and thyroid formation. Developement 2000; 127: 2433-2445.

46 Pellizzari L, D’Elia A, Rustighi A, Manfioletti G, Tell G, Damante G: Expression and function of the homeodomain-containing protein Hex in thyroid cells. Nucleic Acids Res 2000; 28: 25032511.

47 Ang SL, Rossant J: HNF3b is essential for node and notochord formation in mouse development. Cell 1994; 78: 561-574.

$48 \mathrm{Xu} \mathrm{PX}$, Zheng $\mathrm{W}$, Laclef $\mathrm{C}$ et al: Eya1 is required for the morphogenesis of mammalian thymus, parathyroid and thyroid. Development 2002; 129: 3033-3044.

49 Guazzi S, Lonigro R, Pintonello L, Boncinelli E, Di Lauro R, Mavilio F: The thyroid transcription factor-1 gene is a candidate target for regulation by Hox protein. EMBO J 1994; 13: $3339-3347$.
50 Ikeda K, Shaw-White JR, Wert SE, Whitsett JA: Hepatocyte nuclear factor 3 activates transcription of thyroid transcription factor 1 in respiratory epithelial cells. Mol Cell Biol 1996; 16: 3626-3636.

51 Shaw-White JR, Bruno MD, Whitsett JA: GATA-6 activates transcription of thyroid transcription factor-1. I Biol Chem 1999; 274: $2658-2664$

52 Tanaka M, Chen Z, Bartunkova S, Yamasaki N, Izumo S: The cardiac homeobox gene Csx/Nkx2.5 lies genetically upstream of multiple genes essential for heart development. Development 1999; 126: 1269-1280.

53 Devos H, Rodd C, Gagne N, Laframboise R, Van Vliet G: A search for the possible molecular mechanisms of thyroid dysgenesis: sex ratios and associated malformations. J Clin Endocrinol Metab 1999; 84: $2502-2506$

54 Olivieri A, Stazi MA, Mastroiacovo P et al: A population-based study on the frequency of additional congenital malformations in infants with congenital hypothyroidism (1991-1998). J Clin Endocrinol Metab 2002; 87: 557-562.

55 Pauws E, Moreno JC, Tijssen M, Baas F, de Vijlder JJM, Ris-Stalpers C: Serial analysis of gene expression as a tool to assess the human thyroid expression profile and to identify novel thyroidal genes. $J$ Clin Endocrinol Metab 2000; 85: 1923-1927.

Supplementary Information accompanies the paper on European Journal of Human Genetics website (http://www.nature.com/ejhg) 